\title{
Efeitos da queima na dinâmica da biomassa aérea de um campo nativo no Pantanal(1)
}

\author{
Evaldo Luis Cardoso(2), Sandra Mara Araújo Crispim(2), Cristina Aparecida Gonçalves Rodrigues(2) \\ e Waldomiro Barioni Júnior ${ }^{(3)}$
}

\begin{abstract}
Resumo - O objetivo deste trabalho foi avaliar os efeitos da queima na dinâmica da biomassa aérea do estrato herbáceo de um campo nativo do Pantanal com predominância de Andropogon bicornis. A área de estudo foi submetida aos tratamentos sem queima e com queima, ambos sem pastejo. Os dados de biomassa aérea e cobertura do solo foram analisados nos onze meses subseqüentes à queima. A biomassa aérea das áreas com queima apresentou pequeno incremento linear de matéria seca, tornando sua biomassa significativamente menor que a obtida nas áreas sem queima. Andropogon bicornis, Axonopus purpusii e outras espécies apresentaram menor biomassa após a queima, enquanto Mesosetum chaseae foi favorecido pela queima, apresentando maior produção de matéria seca. A ação do fogo removeu praticamente toda a biomassa; a cobertura do solo, trinta dias após a queima, foi de aproximadamente $35 \%$. Somente sete meses depois, a cobertura do solo foi restabelecida, tornando-se semelhante à área sem queima.
\end{abstract}

Termos para indexação: Andropogon bicornis, planta herbácea, estrato vegetal, pastagem nativa, manejo de pastagens.

\section{Effects of burning on the aerial biomass dynamics of a native field in the Pantanal}

\begin{abstract}
This work aimed to assess the effects of burning on the aerial biomass dynamics of aboveground herbaceous plants of a native field of the Pantanal presenting a dominance of Andropogon bicornis. The area under study was treated without burning (control) and with burning, both of them ungrazed. Aerial biomass and soil cover were analyzed during eleven months after burning. The aerial biomass in the with-burning area presented a short linear increment of dry matter. This biomass was expressively shorter than that biomass produced in the without-burning area. Andropogon bicornis, Axonopus purpusii and other species presented less biomass after burning. However, Mesosetum chaseae benefited from burning, presenting higher dry matter production. Burning almost removed all of the vegetal cover and, thirty days after burning, soil cover was approximately $35 \%$. Seven months after burning, vegetal cover was re-established and became similar to the area without burning.
\end{abstract}

Index terms: Andropogon bicornis, herbaceous plants, plant strata, natural pastures, grassland management.

\section{Introdução}

A utilização do fogo como elemento de manejo das áreas de savanas e campos naturais, embora

\footnotetext{
(1) Aceito para publicação em 26 de fevereiro de 2003. Parcialmente financiado pelo Cecitec - Seplan-MS.

(2) Embrapa-Centro de Pesquisa Agropecuária do Pantanal, Caixa Postal 109, CEP 79320-900 Corumbá, MS. E-mail: evaldo@cpap.embrapa.br, scrispim@cpap.embrapa.br, crisagr@cpap.embrapa.br

(3)Embrapa-Centro Nacional de Pesquisa de Suínos e Aves, Caixa Postal 21, CEP 89700-000 Concórdia, SC. E-mail: barioni@cnpsa.embrapa.br
}

muito contestada no meio científico, por entidades ambientalistas e pela sociedade em geral, constitui uma realidade e prática comum em muitas regiões tropicais e subtropicais, especialmente naquelas caracterizadas por estação seca pronunciada. O principal objetivo do uso programado do fogo é reduzir a quantidade de material combustível em áreas sujeitas a longos períodos de estiagem e assim diminuir o risco de incêndios de intensas proporções (Fernandez et al., 1997).

De maneira geral, o efeito do fogo sobre a vegetação pode variar de acordo com as condições ambientais no momento da queima, com o tipo de 
solo da área, freqüência da queima e quantidade de combustível disponível, que determina a intensidade e a duração da queima (Batmanian, 1983; Rodrigues, 1999).

As áreas queimadas na época adequada apresentam aumento ou aceleração da produção primária em comparação com áreas que não sofreram a ação do fogo (Blydenstein, 1963; San José \& Medina, 1975; Sarmiento, 1984). Contudo, a produção de matéria seca das pastagens depende do tempo entre a incidência da queimada e o início da estação de crescimento das plantas; as queimadas que ocorrem quando as plantas encontram-se em fase de crescimento e rebrota natural determinam baixa produtividade primária (Griffin \& Friedel, 1984; James, 1985).

No Pantanal, a queimada é empregada anualmente, entretanto, ao contrário da maioria das áreas de savanas, sua utilização se faz de forma controlada em virtude de características peculiares da região. Por apresentar alternadamente extensas áreas de campos sujeitos a inundações periódicas, cerrados, cerradões e matas, a queimada é feita de forma parcimoniosa.

Conforme Pott (1982), a utilização do fogo no Pantanal é feita de forma seletiva e localizada, procurando eliminar ou conter a expansão de espécies indesejáveis e promover a rebrota das forrageiras de baixa aceitabilidade, sendo comumente queimadas as áreas de "caronal" (predominância de Elyonurus muticus), de "capim-fura-bucho" (Paspalum carinatum e Paspalum stellatum), de "capim-rabo-de-burro" e "rabo-de-lobo" (Andropogon bicornis e Andropogon hypogynus) e cerrados ralos. O mesmo autor destaca que a rebrota promovida pelo fogo parece essencial ao aproveitamento das forrageiras de baixa aceitabilidade, embora cerca de $90 \%$ da fitomassa aérea seja perdida pela queima.

O objetivo deste trabalho foi avaliar o efeito da queima na dinâmica da biomassa aérea do estrato herbáceo de um campo nativo, dominado por Andropogon bicornis, no Pantanal.

\section{Material e Métodos}

O trabalho foi realizado na fazenda Nhumirim, área física experimental da Embrapa-Centro de Pesquisa Agropecuária do Pantanal, localizada no Pantanal da
Nhecolândia (1859' S e 56039' W), no período de agosto de 1996 a julho de 1997.

A área de estudo, regionalmente conhecida por "campo de rabo-de-burro", caracteriza-se pela predominância de A. bicornis. O relevo local é plano e o solo classificado como Areia Quartzosa Hidromórfica distrófica, cuja análise química de amostras coletadas na camada de $0-20 \mathrm{~cm}$ mostrou os seguintes resultados: $\mathrm{pH}$ em água, 5,7; $\mathrm{P}$, $1,6 \mathrm{mg} \mathrm{dm}^{-3} ; \mathrm{Ca}+\mathrm{Mg}, 3,8 \mathrm{mmol}_{\mathrm{c}} \mathrm{dm}^{-3} ; \mathrm{K}, 0,96 \mathrm{mmol}_{\mathrm{c}} \mathrm{dm}^{-3}$ e Al, $0,0 \mathrm{mmol}_{\mathrm{c}} \mathrm{dm}^{-3}$.

A área foi cercada para impedir o pastejo e submetida a dois tratamentos: sem queima (SQ) e com queima (CQ). Em agosto de 1996, logo após as primeiras chuvas, foi realizada a queimada e, a cada 30 dias, durante os 11 meses subseqüentes, foram feitas as avaliações. $\mathrm{O}$ delineamento utilizado foi o inteiramente casualizado com dez repetições em parcelas de 20x20 m.

A biomassa aérea foi determinada pelo método de colheita (Frangi et al., 1980), que consistiu do corte rente ao solo de toda a vegetação herbácea presente em molduras de $1 \mathrm{~m}^{2}$ lançadas aleatoriamente em cada parcela. Todo o material vegetal cortado foi separado da seguinte forma: 1) as espécies Andropogon bicornis, Axonopus purpusii e Mesosetum chaseae foram coletadas individualmente por apresentarem elevada participação na composição botânica e interesse forrageiro; 2) agrupamento de outras espécies com pequena participação na composição botânica; 3) fitomassa seca, constituída por palhada seca. O material coletado foi acondicionado em saco de papel e mantido em estufa a $65^{\circ} \mathrm{C}$ até obtenção do peso constante.

A determinação da cobertura do solo foi realizada por meio da estimativa visual da porcentagem de área da moldura coberta por material vegetal vivo ou morto, antes do corte da vegetação. Em virtude desta variável caracterizar-se por elevada amplitude de variação, os dados foram transformados para a análise estatística em arco seno $(\mathrm{p} / 100)^{0,5}$, visando à homogeneidade da variância. Entretanto, a discussão e as conclusões são referentes aos dados originais.

As análises foram realizadas pelo procedimento GLM do SAS Institute (1999) e o modelo de análise de variância levou em consideração os efeitos dos tratamentos, meses após a queima e suas respectivas interações, comparadas a $5 \%$ de probabilidade.

\section{Resultados e Discussão}

A produção média de biomassa aérea na área com queima foi significativamente menor $(\mathrm{P}<0,05)$, correspondendo a aproximadamente $54 \%$ da obtida 
na área sem queima. Resultados semelhantes, em outras savanas queimadas no Pantanal, foram relatados por Rodrigues (1999) e Cardoso et al. (2000a, 2000b). A produção de biomassa aérea no período subseqüente à queima apresentou incremento linear, decorrente da intensa rebrotação das espécies, estimuladas pelo fogo (Figura 1). Segundo Coutinho (1990), o fogo, ao atuar como elemento seletivo sobre a vegetação, propicia o aparecimento de flora indicadora, estimulando a rápida formação de brotos verdes, independentemente das chuvas, por meio de seu efeito de poda sobre estas plantas, que utilizam reservas armazenadas no sistema radicular.

No entanto, o incremento observado na área com queima, a cada coleta, foi relativamente pequeno, visto que somente após oito meses a produção de matéria seca atingiu valores semelhantes aos da área sem queima. Segundo Pereira \& Peres (1985), pastagens naturais dos cerrados, quando queimadas, têm recuperação muito rápida nos primeiros dias de chuvas subseqüentes. Contudo, após três a cinco meses, as pastagens não queimadas apresentam maior suporte de pastejo, indicando, conforme os autores, que parte dos nutrientes acumulados nas cinzas é imobilizada novamente pelas plantas e parte se perde por lixiviação ou erosão. A menor produção de matéria seca da área queimada e a demora para igua-

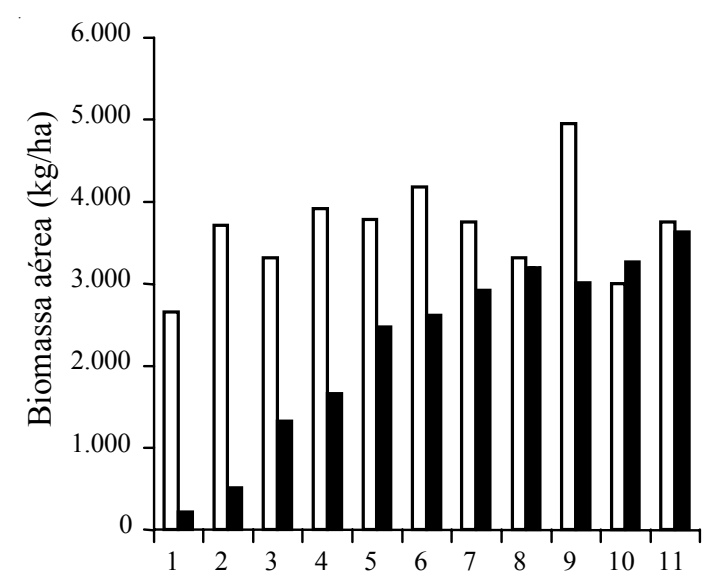

Meses após a queima lar-se novamente à área sem queima podem ser atribuídas, possivelmente, à excessiva redução da área foliar das espécies predominantes, notadamente das espécies cespitosas, retardando o crescimento das plantas e o acúmulo de biomassa aérea. De acordo com Castilhos \& Jacques (1984), o crescimento lento das plantas na fase inicial, após a queimada, é devido à redução do índice de área foliar.

A produção de fitomassa seca foi afetada pela queima, sendo significativamente menor $(\mathrm{P}<0,05)$ que a observada na área sem queima. Sua ausência foi constatada na quase totalidade da área queimada, e baixos valores, próximos a $170 \mathrm{~kg} / \mathrm{ha}$ de MS, foram verificados somente a partir do sétimo mês (Figura 1). Na área sem queima, a produção de fitomassa seca foi expressiva, apresentando valores médios próximos a $3.600 \mathrm{~kg} / \mathrm{ha}$ de MS, destacando-se como o componente de maior participação na composição botânica do campo de $A$. bicornis, constituindo aproximadamente $49 \%$ da matéria seca total. Em outro tipo de savana do Pantanal, sem predomínio por $A$. bicornis, foi constatada a presença de fitomassa seca em área sem queima, constituindo, aproximadamente, $37 \%$ da matéria seca total (Cardoso et al., 2000b).

Segundo Fontaneli et al. (1994), como a fitomassa seca é o componente de maior participação na composição botânica, atenção especial deve ser dada ao

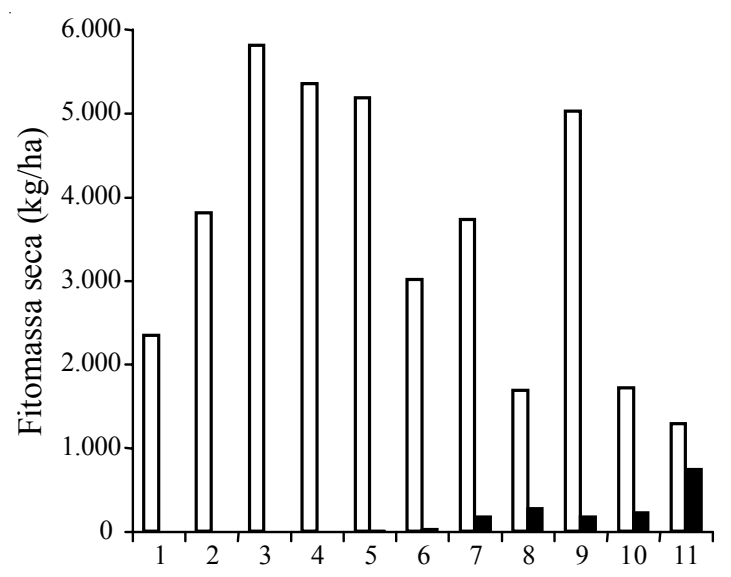

Meses após a queima

Figura 1. Matéria seca da biomassa aérea e fitomassa seca nos tratamentos sem queima ( $\square$ ) e com queima ( $\square$ ) em campo de Andropogon bicornis no Pantanal, durante 11 meses após a queima. 
seu efeito na manutenção das condições físicas, químicas e biológicas da pastagem. Provavelmente, a elevada diferença na quantidade de fitomassa seca presente nas duas áreas deve-se, também, ao acúmulo de macega proveniente de anos anteriores, visto que a referida área de estudo encontrava-se, há muitos anos, sem incidência de queimadas. Brâncio et al. (1997) sugerem que a maior disponibilidade de matéria seca em áreas sem queima é, em parte, explicada pelo efeito residual do material proveniente do crescimento em anos anteriores.

A dinâmica da biomassa aérea, das espécies individualmente estudadas, foi diferenciada entre as duas áreas (Figura 2). Andropogon bicornis, Axonopus purpusii e o componente outras espécies apresentaram biomassa significativamente menor $(\mathrm{P}<0,05)$ na área com queima, correspondendo a aproximadamente $27 \%, 25 \%$ e $27 \%$, respectivamente, da obtida na área sem queima. Por outro lado, Mesosetum chaseae apresentou biomassa significativamente maior $(\mathrm{P}<0,05)$ na área com queima, correspondendo a aproximadamente quatro vezes mais matéria seca que a obtida na área sem queima. O comportamento de $A$. purpusii e $M$. chaseae foi diferente do observado por Cardoso et al. (2000b) em savana gramíneo-lenhosa sem predominância de A. bicornis, evidenciando que a resposta das plantas ao fogo também pode variar de acordo com as condições do ambiente.

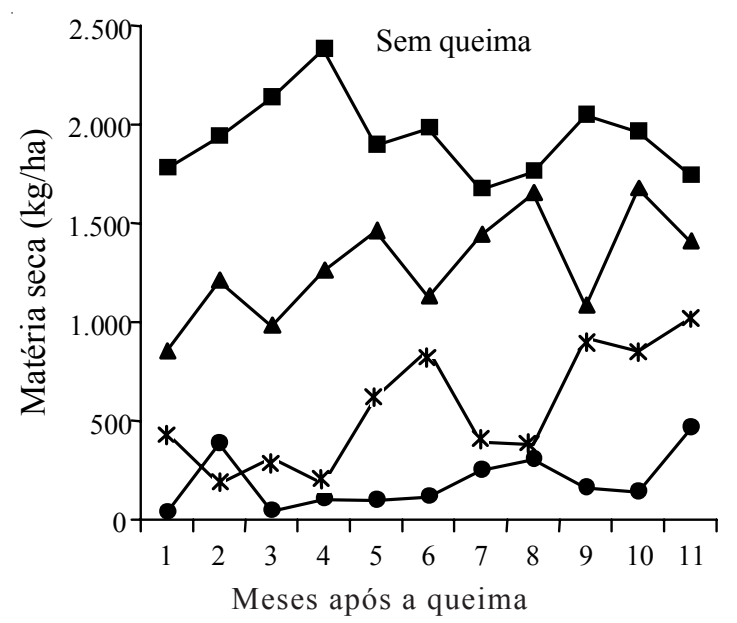

De acordo com Klink \& Solbrig (1996), os efeitos da queima na biomassa são qualitativamente semelhantes onde quer que ocorram. Entretanto, a resposta das plantas varia significativamente tanto entre comunidades como dentro de uma mesma comunidade. Provavelmente, o comportamento diferenciado das espécies do campo nativo de $A$. bicornis em relação à queima pode estar associado ao seu hábito de crescimento. Aquelas espécies que apresentaram menor biomassa aérea, em sua maioria, possuem hábito de crescimento cespitoso, enquanto $M$. chaseae, cuja biomassa foi superior na área com queima, caracteriza-se por grande capacidade de produzir estolhos com afilhamentos intensos. As gramíneas cespitosas, estoloníferas e rizomatosas apresentam formas de crescimento e morfologia distintas, determinando números diferentes de perfilhos e, normalmente, o fogo exerce pressão seletiva sobre gramíneas rizomatosas e cespitosas (Rodrigues, 1999). A maior biomassa de espécies estoloníferas em áreas queimadas pode estar associada à menor competição por água e luz, decorrente da eliminação da macega. Brâncio et al. (1997) atribuíram a rápida rebrotação nas áreas queimadas, provavelmente, ao melhor aproveitamento dos nutrientes provenientes das cinzas e à baixa competição interespecífica por luz.

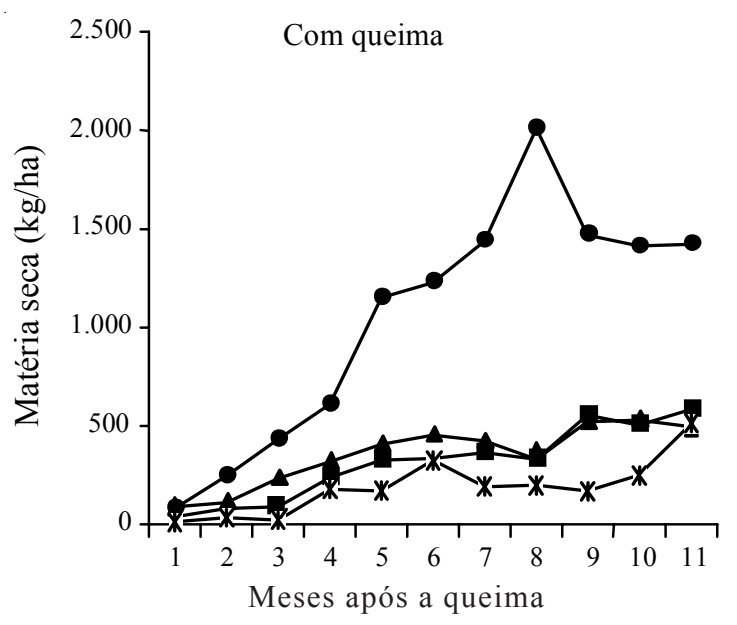

Figura 2. Matéria seca da biomassa aérea de Andropogon bicornis ( $\boldsymbol{\square})$, Axonopus purpusii ( $\mathbf{\Delta})$, Mesosetum chaseae ( ) e outras espécies ( $\boldsymbol{*}$ ) nos tratamentos sem queima e com queima em campo de A. bicornis no Pantanal, durante 11 meses após a queima. 
Em virtude da elevada quantidade de biomassa presente no campo nativo com predomínio de $A$. bicornis, notadamente marcada por fitomassa seca, a queima ocorreu de forma rápida e intensa, tornando o solo totalmente desprovido de cobertura vegetal. Portanto, a cobertura do solo foi severamente comprometida pela combustão do material vegetal, sendo nos seis primeiros meses após a queima, significativamente menor $(\mathrm{P}<0,05)$ que a verificada na área sem queima (Figura 3). Embora o fogo tenha estimulado a rebrota na área queimada, nos primeiros dias após a queima a cobertura do solo foi relativamente baixa, atingindo valores próximos a $35 \%$, expondo demasiadamente o solo à ação das chuvas e ventos. Ao longo do tempo e com a incidência de queimadas periódicas, a sustentabilidade dos solos pode ser comprometida, principalmente considerando-se que no Pantanal os solos caracterizam-se por apresentar baixa fertilidade natural e textura arenosa. Segundo Fontaneli et al. (1994), a exposição do solo provocada pela queima, associada à declividade do terreno, favorece a erosão e a evaporação, restringindo a infiltração e o armazenamento de água, aumentando, conseqüentemente, a vulnerabilidade das plantas à seca.

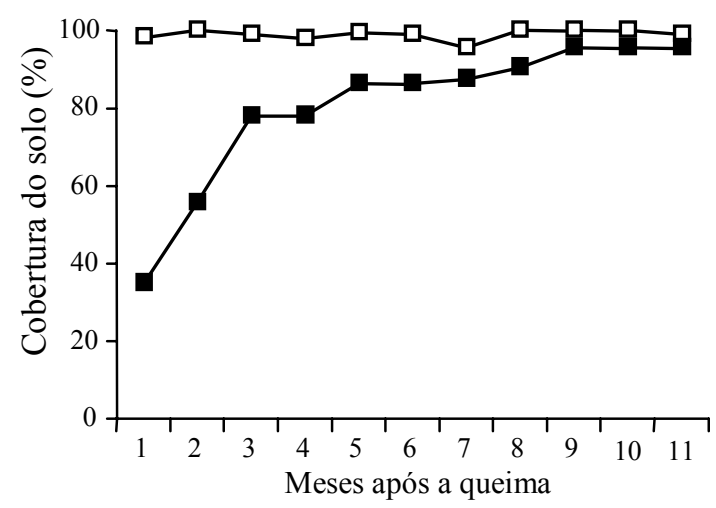

Figura 3. Cobertura do solo nos tratamentos sem queima ( $\square$ ) e com queima ( $\square$ ) em campo de Andropogon bicornis no Pantanal, durante 11 meses após a queima.

\section{Conclusões}

1. A queima do campo nativo com predomínio de Andropogon bicornis afeta a produção e dinâmica da biomassa aérea, reduz a matéria seca e elimina quase totalmente a fitomassa seca, durante os meses subseqüentes à queima.

2. A produção de biomassa aérea das espécies Andropogon bicornis, Axonopus purpusii, Mesosetum chaseae e do componente outras espécies é diferentemente influenciada pela queima; espécies cespitosas são prejudicadas e estoloníferas, favorecidas.

3. A queima reduz expressivamente a cobertura do solo e somente sete meses após são obtidos valores semelhantes aos da área sem queima.

\section{Referências}

BATMANIAN, G. J. Efeitos do fogo sobre a produção primária e a acumulação de nutrientes do estrato rasteiro de um cerrado. 1983. 78 f. Dissertação (Mestrado em Ecologia) - Universidade de Brasília, Brasília, 1983.

BLYDENSTEIN, J. Cambios en la vegetación después de la protección contra el fuego - parte I: el aumento anual en material vegetal en varios sitios quemados y no quemados en la Estación Biológica. Boletín de la Sociedad Venezolana de Ciencias Naturales, Caracas, n. 10, p. 233 238, 1963.

BRÂNCIO, P.A.; NASCIMENTO JÚNIOR，D.; REGAZZI, A. J.; MORAES, E. A.; LEITE, G. G. Avaliação de pastagem nativa dos cerrados submetida à queima anual - 1: composição botânica da dieta de bovinos. Revista Brasileira de Zootecnia, Viçosa, MG, v. 26, n. 3, p. 429-437, 1997.

CARDOSO, E. L.; CRISPIM, S. M. A.; RODRIGUES, C. A. G.; BARIONI JÚNIOR, W. Biomassa aérea e produção primária do estrato herbáceo em campo de Elyonurus muticus submetido à queima anual, no Pantanal. Pesquisa Agropecuária Brasileira, Brasília, v. 35, n. 8 , p. 1501-1507, ago. 2000a.

CARDOSO, E. L.; CRISPIM, S. M. A.; RODRIGUES, C. A. G.; BARIONI JÚNIOR, W. Composição e dinâmica da biomassa aérea após a queima em savana gramíneolenhosa no Pantanal. Pesquisa Agropecuária Brasileira, Brasília, v. 35, n. 11, p. 2309-2316, nov. 2000 b. 
CASTILHOS, Z. M. de S.; JACQUES, A. V. A. Produção e qualidade de uma pastagem natural submetida a tratamentos de introdução de trevo vesiculoso cv. Yuchi (Trifolium vesiculosum Savi), ceifa e queima. Anuário Técnico do Instituto de Pesquisas Zootécnicas Francisco Osório, Porto Alegre, n. 11, p. 103-144, 1984.

COUTINHO, L. M. Fire in the ecology of the Brazilian Cerrado. In: GOLDAMMER, J. C. (Ed.). Fire in the tropical biota. Berlin: Springer, 1990, p. 82-105.

FERNANDEZ, I.; CABANEIRO, A.; CARBALLAS, T. Organic matter changes immediately after a wild-fire in Atlantic Forest soil and comparison with laboratory soil heating. Soil Biology and Biochemistry, Oxford, v. 29, p. 1-11, 1997.

FONTANELI, R. S.; JACQUES, A. V. A.; HENRICH, C.; OERLECKE, D.; SCHUSTER, I.; FONTANELI, R. S. Efeito da ceifa, da queima, do diferimento e da adubação sobre uma pastagem natural. Revista Brasileira de Zootecnia, Viçosa, MG, v. 23, n. 5, p. 719-729, 1994.

FRANGI, J. L.; RONCO, M. G.; SANCHES, N. E.; VICARI, R. L.; ROVETTA, G. S. Efecto del fuego sobre la composición y dinámica de la biomasa de un pastizal de Sierra de la Ventana (Bs. As., Argentina). Darwiniana, Buenos Aires, v. 22, n. 4, p. 565-585, 1980.

GRIFFIN, G. F.; FRIEDEL, M. H. Effects of fire on central Australian rangelands - I: fire and fuel characteristics and changes in herbage and nutrients. Australian Journal of Ecology, Carlton, v. 9, n.4, p. 381-393, 1984.

JAMES, W. An unexpected effect of autumn burning on Tallgrass Prairie. American Midland Naturalist, Notre Dame, v. 114, n. 2, p. 400-403, 1985.
KLINK, C. A.; SOLBRIG, O. T. Efeito do fogo na biodiversidade de plantas do cerrado. In: SARMIENTO, G.; CABIDO, M. (Ed.). Biodiversidad y funcionamiento de pastizales y sabanas en América Latina. Mérida: Cyted y Cielat, 1996. p. 231-244.

PEREIRA, J.; PERES, J. R. R. Manejo de matéria orgânica. In: GOEDERT, W. J. (Ed.). Solos dos cerrados: tecnologia e estratégias de manejo. São Paulo: EmbrapaCPAC/Nobel, 1985. p. 261-284.

POTT, A. Pastagens das sub-regiões dos Paiaguás e da Nhecolândia do Pantanal mato-grossense. Corumbá: Embrapa-UEPAE Corumbá, 1982. 49 p. (Circular Técni$\mathrm{ca}, 10)$.

RODRIGUES, C. A. G. Efeitos do fogo e da presença animal sobre a biomassa aérea e radicular, nutrientes do solo, composição florística, fenologia e dinâmica de um campo de capim-carona (Elyonurus muticus (Spreng.) O. Ktze.) no Pantanal (sub-região da Nhecolândia). 1999. 285 f. Tese (Doutorado em Biologia Vegetal) - Universidade Estadual de Campinas, Campinas, 1999.

SAN JOSÉ, J. J.; MEDINA, E. Effect of fire on organic matter production and water balance in a tropical savanna. In: GOLlEY, F. B.; MEDINA, E. (Ed.). Tropical ecological systems: trends in terrestrial and aquatic research. New York: Springer, 1975. p. 251-264. (Ecological Studies. Analysis and Synthesis, 11).

SARMIENTO, G. The ecology of neotropical savannas. Havard: Harvard University Press, 1984. 235 p.

SAS INSTITUTE (Cary, Estados Unidos). Statistical analysis system: user's guide: release 6.12. Cary, 1999. 1 CD ROM. 